\title{
Metabotropic Glutamate Receptors Mediate Excitatory Transmission in the Nucleus of the Solitary Tract
}

\author{
Steven R. Glaum and Richard J. Miller \\ Department of Pharmacological and Physiological Sciences, The University of Chicago, Chicago, Illinois 60637
}

\begin{abstract}
Following microinjection into the nucleus tractus solitarius (NTS), the effects of glutamate on the baroreceptor reflex are poorly antagonized by kynurenic acid and DL-2-amino5-phosphonovaleric acid, suggesting the possible involvement of metabotropic glutamate receptors in this response. The metabotropic glutamate receptor agonist $1 S, 3 R$-1-aminocyclopentane-1,3-dicarboxylic acid (1S,3R-ACPD) depolarized neurons located medial to the tractus solitarius (TS) at the level of the area postrema in coronal sections of the rat NTS. This effect was mimicked by glutamate and was not blocked by antagonists at $\alpha$-amino-3-hydroxy-5-methylisoxazole-4-propionic acid (AMPA)/kainate or NMDA receptors. 1S,3R-ACPD also produced an inward current under voltage clamp that was not accompanied by a rise in $\left[\mathrm{Ca}^{2+}\right]_{i}$, monitored with the $\mathrm{CA}^{2+}$-sensitive dye fura-2. Conversely, the muscarinic agonist carbachol produced an outward current and a rise in $\left[\mathrm{Ca}^{2+}\right]_{i}, 15,3 R-A C P D$ reduced both the excitatory and the inhibitory postsynaptic current resulting from single electrical stimuli in the region of the TS. Highfrequency stimulation of the TS produced an inward current in the presence of AMPA/kainate and NMDA receptor blockers. This current had similar properties to that produced by 1S,3R-ACPD. Thus, metabotropic glutamate receptors may mediate a component of excitatory transmission in the NTS.
\end{abstract}

The actions of glutamate (GLU) at $\alpha$-amino-3-hydroxy-5-mcthylisoxazole-4-propionic acid (AMPA)/kainate and NMDA receptors have been shown to be responsible for producing fast excitatory synaptic transmission at numerous synapses in the CNS. The properties of these receptors have become increasingly well understood over the last few years and have been shown to mediate many of the physiological and pathological effects of GLU in the brain (Mayer and Westbrook, 1987). However, not all GLU receptors are ligand-gated ion channels. A third type of GLU receptor also exists that is linked to one or more G-proteins and effector systems. This receptor has sometimes been described as the "metabotropic" GLU receptor (Sugiyama et al., 1989; Schoepp et al., 1990). Molecular biological

\footnotetext{
Received Oct. 10, 1991; revised Dec. 26, 1991; accepted Jan. 13, 1992.

We thank Dr. Shawn N. Murphy for preparing the computer software used in the present study and Timothy J. Hodgen for subscquent programming assistance. S.R.G. was supported by National Institutes of Health Grant T32HL7237-14. Additional support came from the Brain Research Foundation, Digestive Disease Care Center Award 1P30DK42086-01, and U.S. Public Health Service Grants DA-02575, DA-02121, and MH-40165 to R.J.M.

Correspondence should be addressed to Richard J. Miller, Ph.D., Department of Pharmacological and Physiolngical Sciences, The University of Chicago, 947 East 58th Street, Chicago, IL 60637.

Copyright (C) 1992 Society for Neuroscience $0270-6474 / 92 / 122251-08 \$ 05.00 / 0$
}

studies have revealed that this protein has a sequence related to other members of the heptahelical G-protein-linked receptor superfamily (Houamed et al., 1991; Masu et al., 1991). The initial effect associated with metabotropic GLU receptor activation was stimulation of phospholipase $C$ in both neurons and astrocytes, resulting in the synthesis of inositol trisphosphate $\left(\mathrm{IP}_{3}\right)$ and mobilization of $\mathrm{Ca}^{2+}$ from intracellular stores (Schoepp et al., 1990; reviewed in Miller, 1991). Although metabotropic GLU receptors are widely distributed in the CNS (Horikoshi et al., 1989), the ncurophysiological conscquences of mctabotropic receptor activation are only now becoming evident (Miller, 1991). One reason for this has been the recent introduction of $1 S, 3 R$ 1 -aminocyclopentane-1,3-dicarboxylic acid (1S,3R-ACPD, or trans-ACPD), which is a rather selective agonist at such receptors (Palmer et al., 1989; Manzoni et al., 1990). Thus, under the appropriate circumstances, the effects of $1 S, 3 R$-ACPD can be taken as indicating the involvement of metabotropic GLU receptors. Initial experiments have shown that $1 S, 3 R$-ACPD can produce a variety of electrophysiological effects, including slow depolarization (Stratton et al., 1989, 1990; Charpak et al., 1990; Charpak and Gähwiler, 1991; Zheng and Gallagher, 1991), inhibition of spike accommodation (Stratton et al., 1989, 1990; Baskys et al., 1990a,b; Charpak et al., 1990; Charpak and Gähwiler, 1991), and presynaptic inhibition (Baskys and Malenka, 1991; Desai and Conn, 1991; Lovinger, 1991 ; Pacelli and Kelso, 1991). However, many questions remain to be addressed. For example, what is the complete repertoire of cellular effects produced by metabotropic receptors, and when are such receptors activated by synaptically released GLU?

In order to answer such questions, our attention was drawn to the nucleus of the solitary tract (NTS). The NTS is the primary medullary region for the coordination of a variety of cardiovascular, respiratory, and visceral reflexes. Neurons within the rostrocaudal subdivision of the NTS, adjacent to the area postrema and medial to the tractus solitarius (TS), have been shown to affect baroreceptor (Leone and Gordon, 1989) and BreuerHering (Bonham and McCrimmon, 1990) reflexes. GLU appears to be the primary neurotransmitter used by afferent projections to the NTS from the periphery (Meeley et al., 1989). Furthermore, agonists acting at AMPA/kainate or NMDA receptors appear to activate the majority of neurons within the NTS (Drewe et al., 1990). When microinjected into the NTS in vivo, the GLU receptor antagonist kynurenate has been shown to inhibit the baroreceptor reflex, as well as the hypotensive and bradycardic effects of injected kainate or NMDA (Talman, 1989). Curiously, however, the effects of exogenous GLU or quisqualate were poorly inhibited by kynurenate (Leone and Gordon, 1989; Talman, 1989). We took this observation to indicate 
Figure 1. Representative voltage, current, and $\left[\mathrm{Ca}^{2+}\right]_{i}$ measurements from an NTS neuron exposed to $1 S, 3 R$-ACPD. $A$, Acute exposure to $50 \mu \mathrm{M} 1 S, 3 R$ $A C P D$ in the presence of the GABA antagonist $\mathrm{BIC}(10 \mu \mathrm{M})$ produced longlasting depolarization and an increase in somatic $\left[\mathrm{Ca}^{2+}\right]_{\text {in }}$ in NS neurons. Resting $V_{m}$ at the start of the trace $\approx$ $-50 \mathrm{mV}$. The break in the graph encompasses 4 min when $\left[\mathrm{Ca}^{2+}\right]_{i}$ and $V_{m}$ slowly decayed back to resting levels. $B$, The neuron in $A$ was voltage clamped at its resting $V_{m}$ in the presence of the GLU receptor antagonists DNQX (1 $\mu \mathrm{M})$, APV $(50 \mu \mathrm{M})$, and BIC $(10 \mu \mathrm{M})$. The muscarinic agonist carbachol (10 $\mu \mathrm{M})$ produced an outward current and an increase in $\left[\mathrm{Ca}^{2+}\right]_{i} .1 S, 3 R \cdot A C P D(50$ $\mu \mathrm{M})$ produced an inward current with no change in $\left[\mathrm{Ca}^{2+}\right]_{i}$.

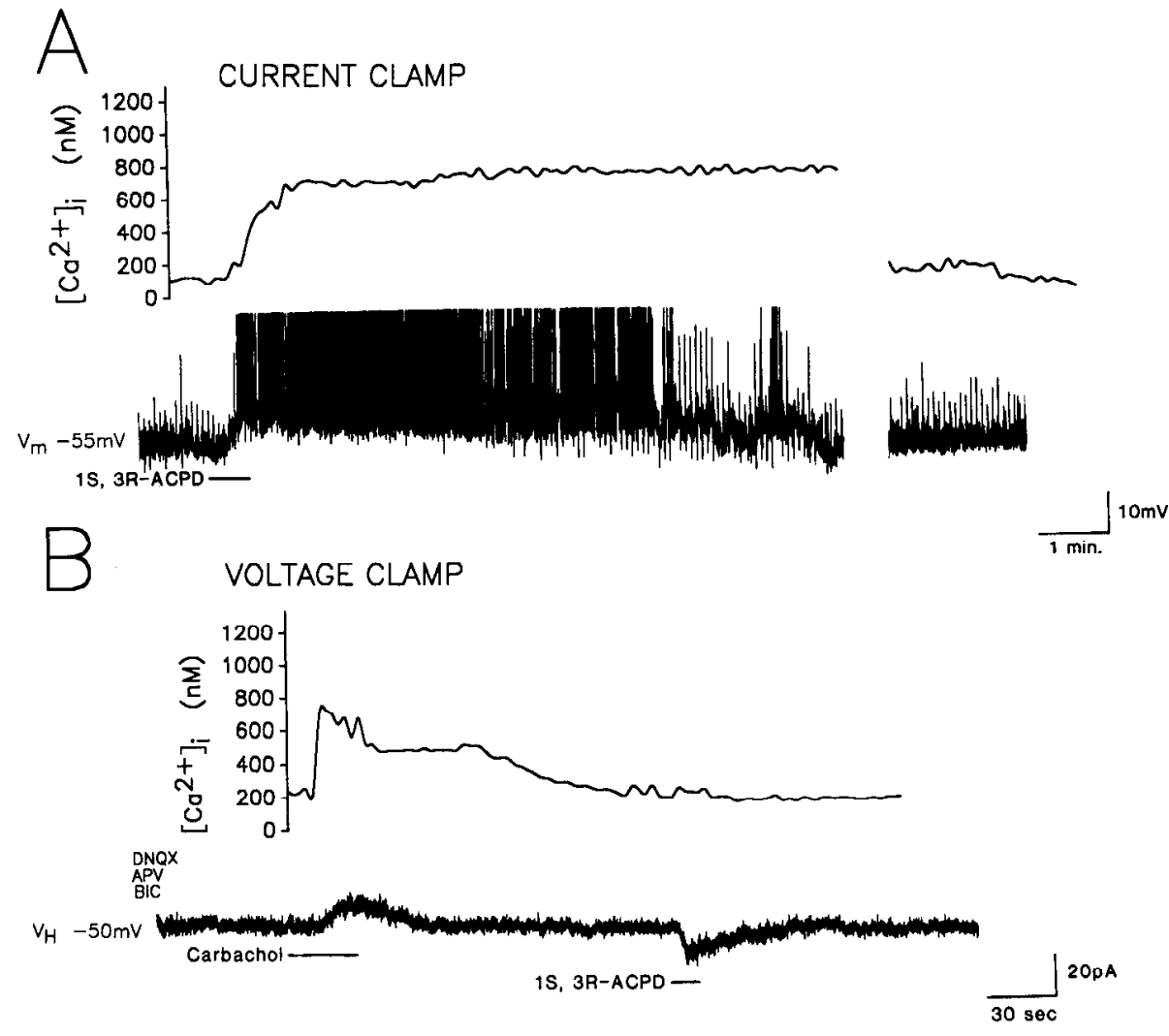

that some of the actions of GLU in this nucleus might be mediated by additional types of GLU receptors. In the present study we have examined the response of neurons within the NTS to application of $1 S, 3 R$-ACPD utilizing whole-cell patch recording in coronal brainstem slices. In order to be able to define the relationship between the effects observed and those previously reported on $\left[\mathrm{Ca}^{2+}\right]_{i}$, these measurements were combined with simultaneous monitoring of $\left[\mathrm{Ca}^{2+}\right]_{i}$ in the same cells. In addition, the effects of $1 S, 3 R$-ACPD on electrically evoked neurotransmitter release were also assessed. We report that $1 S, 3 R$-ACPD produces both pre- and postsynaptic responses within the NTS that may be of significance for cardiovascular reflexes in vivo.

\section{Materials and Methods}

Electrophysiology. Sprague-Dawley rats of either sex, aged between 4 and 6 weeks, were given overdoses of ether, and the whole brain, including the cervical spinal cord, was rapidly removed and placed in icecold artificial cerebrospinal fluid (aCSF), which contained (in $\mathrm{mm}$ ) NaCl, $125 ; \mathrm{NaHCO}_{3}, 26.2 ; \mathrm{NaH}_{2} \mathrm{PO}_{4}, 1 ; \mathrm{KCl}, 3 ; \mathrm{MgSO}_{4}, 1.5 ; \mathrm{CaCl}_{2}, 2.5$; and glucose, 10. The final osmolarity of aCSF was between 315 and 330 mOsm. Transverse $300 \mu \mathrm{m}$ slices containing the NTS were prepared and placed in a holding chamber filled with $23^{\circ} \mathrm{C}$ aCSF and continuously bubbled with a $95 \% / 5 \%$ mixture of $\mathrm{O}_{2} / \mathrm{CO}_{2}$. Following a $1 \mathrm{hr}$ recovery, a single slice was transferred to the recording chamber (volume of 1 $\mathrm{ml}$ ), where it was submerged and held in place between two nets and continuously perfused $(4-5 \mathrm{ml} / \mathrm{min})$ with oxygenated $\mathrm{aCSF}$ at room temperature.

Patch electrodes were filled with a solution containing (in $\mathrm{mm}$ ) $\mathrm{K}^{+}$ gluconate, $145 ; \mathrm{MgCl}_{2}, 2$; HEPES, 5; fura-2 pentapotassium salt, 0.1; and $\mathrm{K}_{2}-\mathrm{ATP}, 5$. Pipette solutions were adjusted to a $\mathrm{pH}$ of 7.2 with $\mathrm{KOH}$ and had an osmolarity of 305-315 mOsm. Electrode resistance was between 2 and $5 \mathrm{M} \Omega$. Neurons were approached under visual inspection of the slice at $400 \times$ magnification with Hoffman modified optics. Seals in excess of $5 \mathrm{G} \Omega$ were obtained and background fluorescence determined immediately prior to whole-cell recording. Recordings were obtained from cells with stable membrane potentials $\left(V_{m}\right)$ greater than $-50 \mathrm{mV}$, overshooting action potentials, and access resistance $<25 \mathrm{M} \Omega$. Recordings were made with an Axoclamp 2A amplifier (Axon Instruments) in discontinuous single-electrode current or voltage clamp, with switching frequencies that allowed for complete sellling of the headstage signal $(4-14 \mathrm{kHz})$.

Synaptic stimulation was carried out by placing a bipolar tungsten stimulating electrode in the region of the ipsilateral tractus solitarius (TS). Single, subthreshold stimuli were delivered (5-200 $\mu \mathrm{sec}, 1-30 \mathrm{~V}$ ) at $5-10 \mathrm{sec}$ intervals. In the majority of cells $(\sim 75 \%)$, in which evidence of both evoked IPSPs and EPSPs was observed, EPSPs were pharmacologically isolated by the addition of the $\mathrm{GABA}_{\mathrm{A}}$ antagonist bicuculline (BIC; $10 \mu \mathrm{M}$ ). Unless otherwise indicated, the duration and intensity of synaptic stimulation were then adjusted to attain highly reproducible responses. Evoked IPSPs were similarly isolated by the addition of the GLU receptor antagonists 6,7-dinitroquinoxaline-2,3-dione (DNQX; 1 $\mu \mathrm{M})$ and DL-2-amino-5-phosphonovaleric acid (APV; $50 \mu \mathrm{M}$ ). The combined application of antagonists blocked all discernable evoked synaptic activity, even at stimulus intensities $10 \times$ the control value. All drugs were applied in the perfusate. The osmolarity of all drug-containing aCSF solutions was found to be within the range of the control aCSF. A delay in the change of bath solutions inherent to the perfusion system was estimated between 15 and $30 \mathrm{sec}$. Figures indicating the application of drugs have been corrected for this delay.

Data were filtered at $3 \mathrm{kHz}$, stored on a chart recorder (Gould), digitized at $125 \mathrm{kHz}$ by a computer-driven analogue-to-digital converter (INDEC Systems), and stored on hard disk for subsequent analysis.

The peak amplitude of EPSPs and IPSPs was quantitated following pharmacological isolation by the addition of BIC or DNQX/APV, respectively. Comparisons were made between the average peak amplitude of five stimuli immediately prior to the application of drugs and the average of five values obtained at the apparent peak of the response.

Under conditions of voltage clamp, evoked excitatory (EPSCs) and inhibitory (IPSCs) postsynaptic currents were pharmacologically isolated and averaged as before at holding potentials $\left(V_{h}\right)$ between -50 and $-65 \mathrm{mV}$.

Pooled data on evoked events were obtained from three or more neurons and expressed as the mean \pm SEM.

$\left[\mathrm{Ca}^{2+}\right]_{\mathrm{i}}$ measurements. For fura-2 epiffuorescence measurements, light from an Xe lamp dual monochromator light source (PTI) was split by 


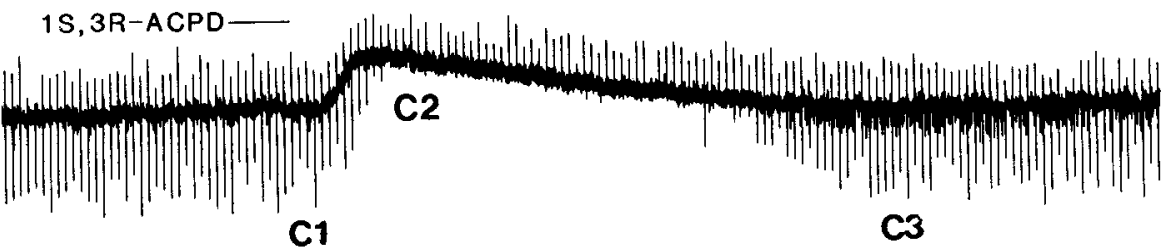

IPSP in DNQX/APV
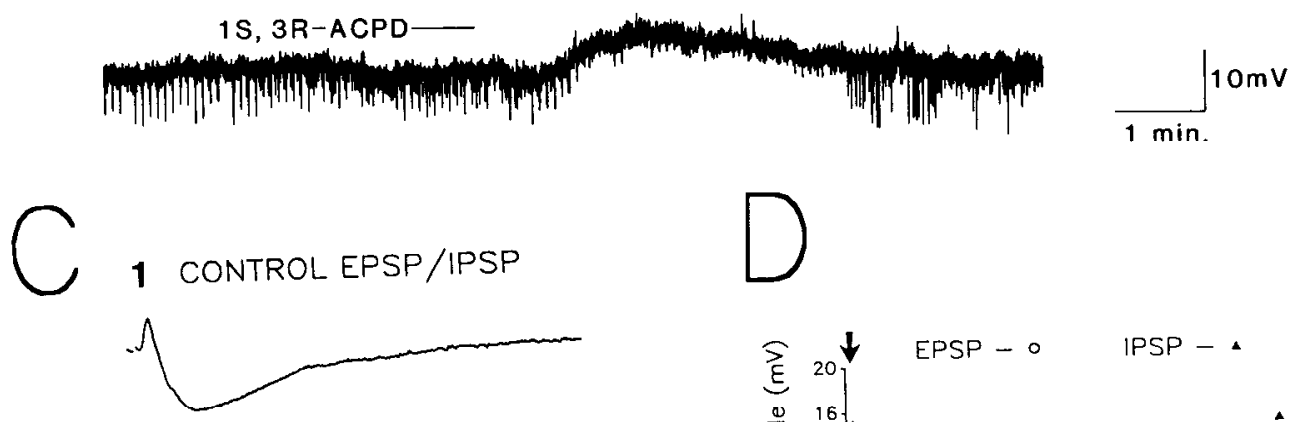

2 EPSP/IPSP in $1 S, 3 R-A C P D$
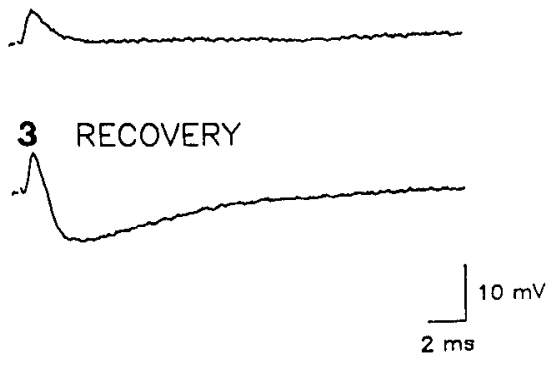

Figure 2. Depolarizing responses and depression of evoked synaptic transmission recorded in an NTS neuron. $A$, Bath application of $1 S, 3 R$-ACPD (50 $\mu \mathrm{M})$ produced a slow depolarization of this neuron and a reduction in IPSPs (downward deflections on trace) evoked by single subthreshold electrical stimulation in the region of the tractus solitarius $(1 \times 5 \mathrm{sec})$. Evoked EPSPs $(u p$ ward deflections) were unaffected by $1 S, 3 R$-ACPD in this neuron. In $B$, the pre- and postsynaptic effects of $1 S, 3 R$ ACPD on the cell in $A$ were preserved in the presence of the ionotropic GLU receptor antagonists DNQX $(1 \mu \mathrm{M})$ and APV $(50 \mu \mathrm{M})$. Although the stimulus strength was unchanged from $A$, note the decrease in the IPSP amplitude. This reflects the mixed direct (monosynaptic) and indirect (polysynaptic, DNQX) APV-sensitive) driving force underlying the evoked IPSP. Resting $V_{m}$ at the start of $A$ and $B$ was $-61 \mathrm{mV}$. $C$. Averaged (five stimuli), higher-time-resolution traces of the evoked EPSP/IPSP complex and the effect of $1 S, 3 R$-ACPD taken from the cell in $A$ at points $C l$, $C 2$, and $C 3$. Note the broadening of the EPSP (2) during the block of the IPSP by $1 S, 3 R-A C P D$. Similar observations following the addition of BIC suggest that, under control conditions, the short latency of the IPSP curtails the monosynaptic EPSP. $D$, Plot of peak evoked PSP amplitude for each evoked EPSP/ IPSP complex, taken from cell in $A$ immediately following the addition of $1 S, 3 R$-ACPD (arrow). means of a computer-driven chopper into 340 and $380 \mathrm{~nm}$ excitation wavelengths ( $4 \mathrm{~nm}$ bandwidth). The collminated beam was passed through a Zeiss $40 \times$ water immersion objective mounted on a Leitz upright microscope, with emitted fluorescence from a $10-40 \mu \mathrm{m}^{2}$ area encompassing the soma passed through a $480 \mathrm{~nm}$ longpass filter into a photomultiplier tube (Thorn/EMI). Synchronized digital conversion (125 $\mathrm{kHz}$ ) of the analog signal (8 msec/wavelength) was performed by a software package adapted by $S$. Murphy from previously described software (Murphy and Miller, 1988). Calculation of $\left[\mathrm{Ca}^{2+}\right]_{i}$ was performed by the method of Grynkiewicz et al. (1985), with calibrations made as previously described (Murphy and Miller, 1988).

\section{Results}

$1 S, 3 R$-ACPD produced several effects on neurons in the NTS. The first of these is illustratcd in Figurc 1. Concentrations of $1 S, 3 R$-ACPD between 5 and $50 \mu \mathrm{M}$ depolarized neurons, sometimes bringing them to the threshold for firing action potentials. It can be seen that accompanying this response there was a large rise in $\left[\mathrm{Ca}^{2+}\right]_{i}$, from a basal level of $128.3 \pm 16.0 \mathrm{nM}$ to a peak level of $800.2 \pm 58.9 \mathrm{~nm}(n=6)$. Following washout of the $1 S, 3 R$-ACPD, the response gradually subsided. In particular, the $\left[\mathrm{Ca}^{2+}\right]_{i}$ usually took $3-5 \mathrm{~min}$ to return to baseline levels (Fig. $1 A)$. In cells that depolarized but did not reach action potential threshold, no increase in $\left[\mathrm{Ca}^{2+}\right]_{i}$ was noted (basal $\left[\mathrm{Ca}^{2+}\right]_{i}=135.7$ $\pm 10.1 \mathrm{~nm}$; in the presence of $50 \mu \mathrm{M} 1 S, 3 R$-ACPD, $\left[\mathrm{Ca}^{2+}\right]_{i}=$ $155.3 \pm 17.3 \mathrm{nM} ; n=7$ ). The mean depolarization following acute application of $50 \mu \mathrm{M} 1 S, 3 R$-ACPD to neurons examined under current-clamp conditions was $5.8 \pm 0.8 \mathrm{mV}(n=13)$, from a resting $V_{m}$ between -63 and $-52 \mathrm{mV}$.

When neurons were voltage clamped near their resting membrane potentials $(-50$ to $-60 \mathrm{mV})$ in the presence of DNQX, APV, and BIC (Fig. 1B), 1S,3R-ACPD produced an inward current that appeared to be independent of a rise in the somatic $\left[\mathrm{Ca}^{2+}\right]_{i}\left(\right.$ basal $\left[\mathrm{Ca}^{2+}\right]_{i}=117.7 \pm 32.6 \mathrm{nM}$; in the presence of 50 $\mu \mathrm{M} 1 S, 3 R$-ACPD, $\left[\mathrm{Ca}^{2+}\right]_{i}=128.2 \pm 5.3 \mathrm{nM} ; n=7$ ). In contrast, the muscarinic agonist carbachol produced an outward current that was preceded by a robust rise in $\left[\mathrm{Ca}^{2+}\right]_{i}$ (basal $\left[\mathrm{Ca}^{2+}\right]_{i}=$ $192.0 \pm 9.7 \mathrm{nM}$; in the presence of $10 \mu \mathrm{M}$ carbachol, peak $\left[\mathrm{Ca}^{2+}\right]_{i}$ $=985.7 \pm 136.4 \mathrm{nM} ; n=3$ ). In these experiments the lack of effect of $1 S, 3 R$-ACPD on $\left[\mathrm{Ca}^{2+}\right]_{i}$ was not due to a prior depletion of intracellular $\mathrm{Ca}^{2+}$ stores following muscarinic receptor activation, as the same result was also obtained when $1 S, 3 R$-ACPD was applied to cells prior to other stimuli (e.g., Fig. $4 C$ ).

In addition to producing postsynaptic depolarization, $1 S, 3 R$ ACPD also reduced both components of the evoked glutama- 

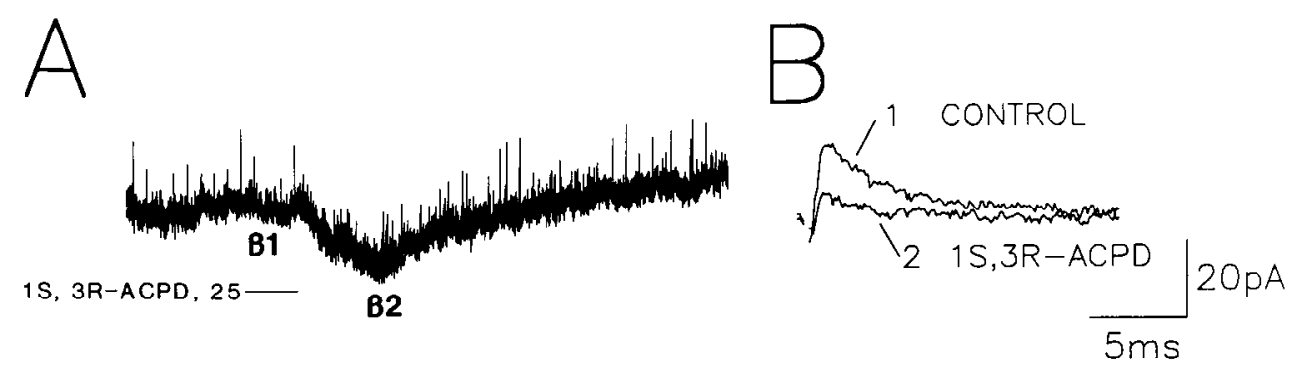

Figure 3. Pre- and postsynaptic effects of $1 S, 3 R$-ACPD were reproduced by exogenous GLU. $A$, Continuous chart record of a current trace following sequential exposure to $1 S .3 R$-ACPD (25 $\mu \mathrm{M})$ and GLU (25 and $100 \mu \mathrm{M}$ ) in the presence of $1 \mu \mathrm{M}$ DNQX and $50 \mu \mathrm{M}$ APV. Cell was clamped at $-60 \mathrm{mV}$. IPSCs (upward deflections on trace) were evoked by electrical $(1 \times 10 \mathrm{sec})$ stimulation in the rcgion of the TS. $B$, Higher-time-resolution, averaged $(n=5)$ traces of the evoked IPSC, taken from cell in $A$ at points $B 1$ and $B 2$, illustrating control and peak inhibition by $1 S, 3 R$-ACPD. $C$, Plot of $1 S, 3 R$-ACPD and GLU effects on individual IPSC amplitude from cell in $A$.

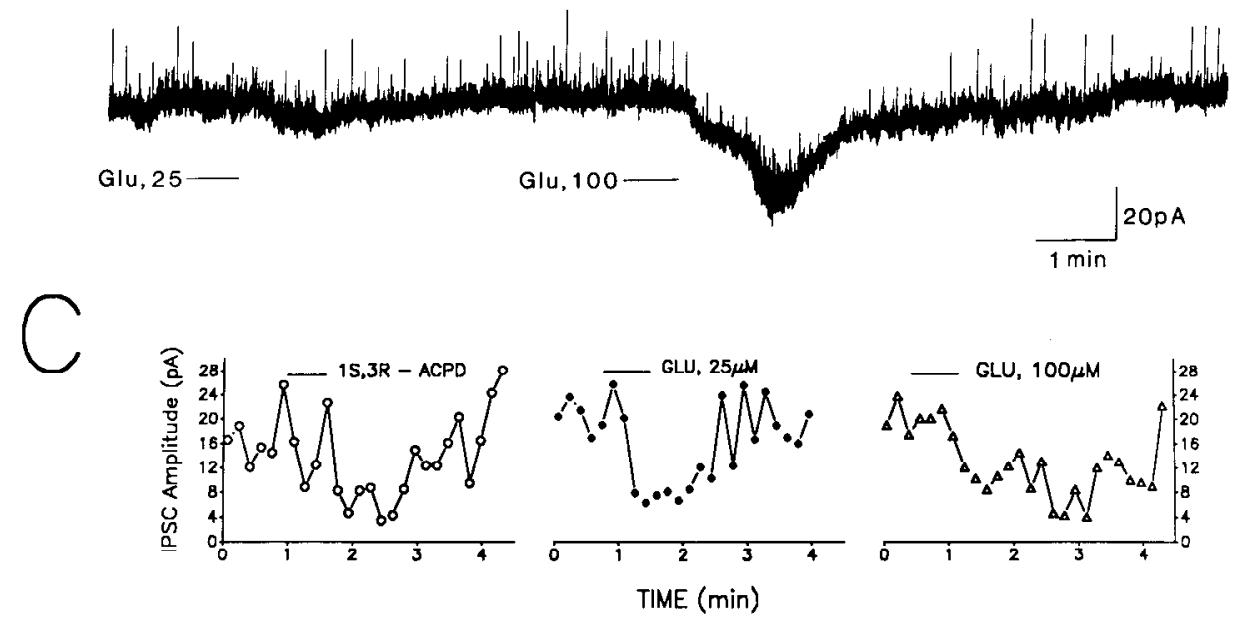

tergic EPSP/GABAergic IPSP complex produced by a single subthreshold stimulus in the region of the TS (Fig. 2). Note the broadening of the EPSP during the block of the IPSP by $1 S, 3 R$ ACPD. Similar observations using BIC suggest that the short latency of the IPSP curtails the preceding EPSP. Thus, in order to evaluate precisely the effects of $1 S, 3 R$-ACPD on evoked synaptic activity, the relative contributions of GABA or GLU were first eliminated by pharmacological means. In the example illustrated in Figure 2, the EPSP (upward deflection on trace) was eliminated by the addition of the glutamate receptor antagonists DNQX and APV, following the evoked IPSP (downward deflection on trace) to be clearly observed. The decrease in the amplitude of the IPSP in the presence of DNQX/APV (compare Fig. $2 A, B$ ) reflects the mixed direct (monosynaptic) and indirect (polysynaptic, AMPA/NMDA receptor-mediated) nature of inhibitory events driven by afferent inputs to the TS.

\begin{tabular}{|c|c|c|}
\hline & Mean \pm SE $(\%)$ & $n$ \\
\hline \multicolumn{3}{|c|}{ Current clamp } \\
\hline EPSPs & $-67.1 \pm 5.9$ & 20 \\
\hline IPSPs & $-95.5 \pm 2.6$ & 6 \\
\hline \multicolumn{3}{|c|}{ Voltage clamp } \\
\hline EPSCs & $-53.0 \pm 6.6$ & 12 \\
\hline IPSCs & $-92.2 \pm 4.4$ & 8 \\
\hline
\end{tabular}

Synaptic currents or potentials were evoked by subthreshold electrical stimuli in the region of the tractus solitarius. Excitatory activity was recorded in the presence of BIC $(10 \mu \mathrm{M})$. Inhibitory activity was recorded in the presence of DNQX $(1 \mu \mathrm{M})$ and APV $(50 \mu \mathrm{M})$. The amplitudes of five consecutive synaptic events were averaged, normalized to $100 \%$, and compared to the averaged amplitude at the peak of the $1 S, 3 R$-ACPD response. Individual percentage inhihitory effects were pooled. Synaptic potentials were recorded at the resting $V_{m}$. Synaptic currents were recorded at $V_{h}$ between -50 and $60 \mathrm{mV}$.
Although $1 S, 3 R$-ACPD was observed to block the remaining monosynaptic IPSP completely in virtually every instance, this was not so for monosynaptic EPSPs measured in the presence of BIC, where inhibition was variable and less pronounced (see below). Both the postsynaptic inward current and presynaptic inhibitory effect on evoked IPSP/Cs produced by $1 S, 3 R$-ACPD were also observed following the application of GLU in the presence of DNQX and APV as shown in Figure 3. The peak inhibition by $25 \mu \mathrm{M}$ GLU was similar to that of $100 \mu \mathrm{M}$ GLU, possibly indicating that the effectiveness of GLU was limited by uptake systems preserved in the slice.

The effects of $1 S, 3 R$-ACPD on evoked postsynaptic potentials (PSPs) and currents (PSCs) measured under current- and voltage-clamp conditions, respectively, are summarized in Table 1. The higher SE obtained for $1 S, 3 R$-ACPD effects on pharmacologically isolated evoked excitatory events reflects the greater variability of inhibition observed in these experiments. Although the majority of neurons (56 out of 61) responded to $1 S, 3 R$-ACPD as detailed above, cxcitatory transmission was completely inhibited in two cells without a discernable inward current, as illustrated in Figure $4 A$. Furthermore, an additional three cells responded with an inward current but without significant inhibition of the EPSC evaluated in the presence of BIC (Fig. 4C).

In order to examine further the nature of the postsynaptic response to $1 S, 3 R$-ACPD, whole-cell $I / V^{r}$ curves in the presence of synaptic blockers were generated under control conditions and during the peak of inward current, as illustrated in Figure 5 . Neurons exposed to $1 S, 3 R$-ACPD exhibited an inward current associated with a decrease in the slope conductance of the $I / V$ relationship. Because the $1 S, 3 R$-ACPD current was relatively small $(<50 \mathrm{pA})$ at potentials near the resting potential and appeared to reverse in the region of strong rectification, an alternative method was used to estimate the reversal potential 


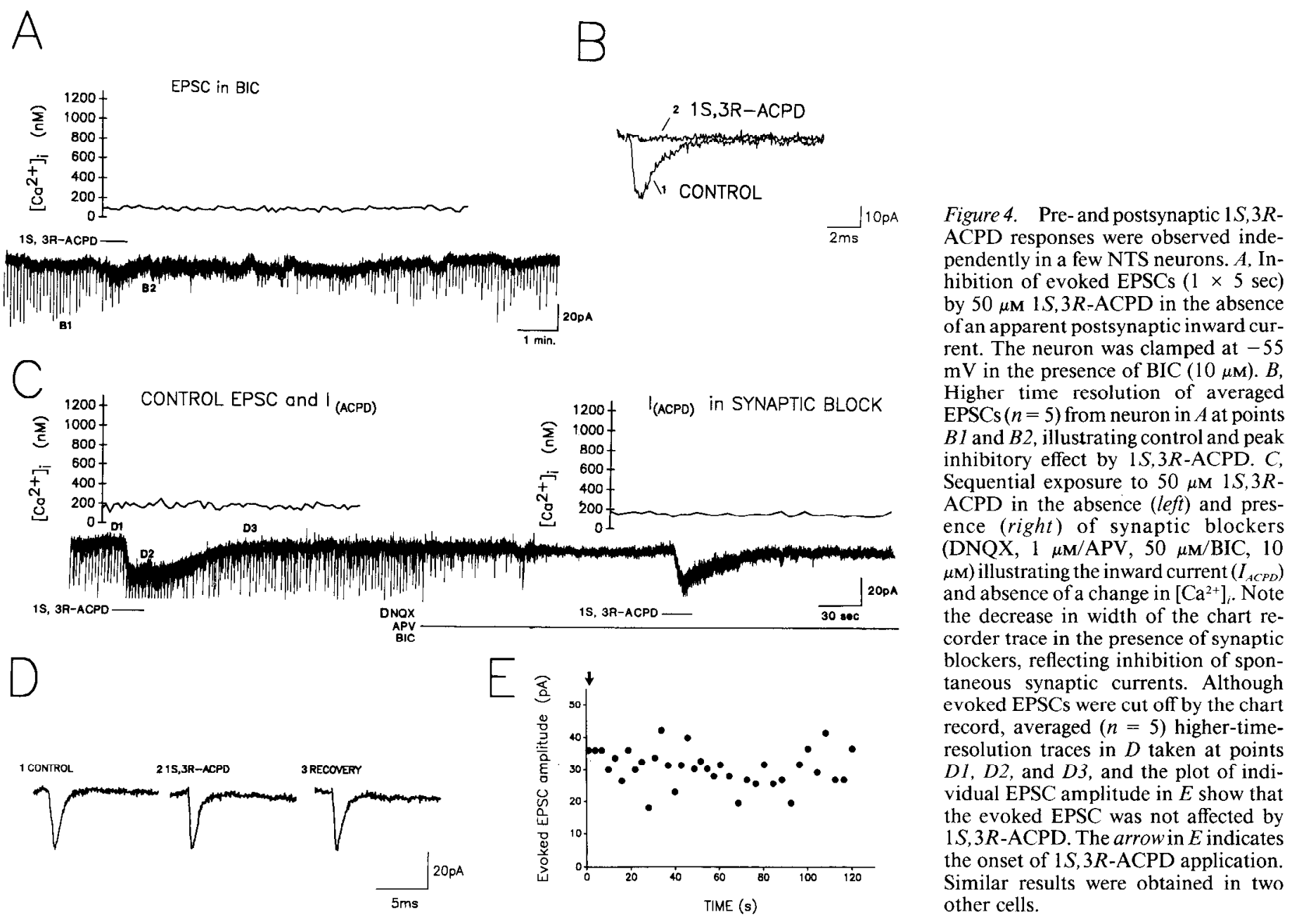

for the current. Cells were clamped at potentials between -90 and $0 \mathrm{mV}$, and the peak current was obtained following $30 \mathrm{sec}$ bath application of $1 S, 3 R$-ACPD applied at $15 \mathrm{~min}$ intervals. Cells were returned to the control $(-50 \mathrm{mV}$ test potential) and exposed to $1 S, 3 R-\Lambda C P D$ between exposures at the other holding potentials to address the question of desensitization. The peak current at the control holding potential varied by $<5 \%$ using this paradigm, suggesting an absence of strong desensitization. The pooled results of this series of experiments are illustrated in Figure $5 B$. The estimated reversal potential for the $1 S, 3 R$-ACPD induced current was $\sim-75 \mathrm{mV}$.

The current produced by $1 S, 3 R$-ACPD was occluded by $\mathrm{Ba}^{2+}$ (1-5 mM; $n=5$ ). Thus, while $\mathrm{Ba}^{2+}$ itself produced an inward current, no additional current was evident following the combined application of $\mathrm{Ba}^{2+}$ and $1 S, 3 R-\mathrm{ACPD}$, as illustrated in Figure $5 C$. As the $I / V$ curves for $\mathrm{Ba}^{2+}, 1 S, 3 R$-ACPD, or a combination of the two were identical, both $1 S, 3 R$-ACPD and $\mathrm{Ba}^{2+}$ seemed to be reducing a similar membrane conductance.

The effects of $1 S, 3 R$-ACPD ( $5 \mu \mathrm{M})$ were not blocked by 2-amino-3-phosphonoproprionic (L-AP3; $50 \mu \mathrm{M} ; n=5$ ). This compound has been shown to inhibit agonist actions at metabotropic glutamate receptors in some instances (Palmer et al., 1989; Schoepp and Johnson, 1989; Schoepp et al., 1990). Higher concentrations of L-AP3 induced nonspecific membrane effects and could not therefore be used. The addition of the $\mathrm{K}^{+}$channel blocker $\mathrm{Cs}^{+}(5 \mathrm{~mm})$ or the isosmotic substitution of $25 \mathrm{~mm}$ tetraethylammonium (TEA) for part of the extracellular $\mathrm{Na}^{+}$ also failed to block the $1 S, 3 R$-ACPD $(50 \mu \mathbf{M})$-induced current in these cells ( $n=3$ each).

In order to determine whether synaptically released GLU could activate postsynaptic metabotropic responses in the NTS, stimulus trains of increasing frequency and duration wcre applied to the region of the TS. Stimulus intensity was first established at a level sufficient to evoke a subthreshold, monosynaptic $\mathrm{EPSP} / \mathrm{C}$ in the absence of synaptic blockers. Slices were then perfused with DNQX/APV/BIC. No residual PSP or PSC was observed following single stimuli at the frequencies $(0.1-0.2 \mathrm{~Hz})$ used in the previously detailed experiments. Stimulus frequency and train duration were then altemately increased until discernable current or voltage responses were obtained. Following this paradigm, the most sensitive cell $(n=11)$ produced a 10 pA inward current from a $V_{h}=-50 \mathrm{mV}$ after a $100 \mathrm{msec}, 20$ $\mathrm{Hz}$ stimulus train. Peak inward current (18 pA) was obtained with a $300 \mathrm{msec}, 50 \mathrm{~Hz}$ train. In the remaining neurons, stimulus trains of $>100 \mathrm{msec},>20 \mathrm{~Hz}$ were necessary to observe postsynaptic responses reminiscent of those produced by exogenously applied $1 S, 3 R$-ACPD. The reversal potential of the inward current produced was $-73 \pm 3 \mathrm{mV}(n=3)$, similar to that produced by $1 S, 3 R$-ACPD itself. Furthermore, the inward current was not accompanied by a rise in $\left[\mathrm{Ca}^{2+}\right]_{i \text {. }}$ The synaptically mediated postsynaptic response was occluded following the addition of $1-5 \mathrm{mM} \mathrm{Ba}^{2+}(n=5)$, similar to the findings with $1 S, 3 R$-ACPD itself (Fig. 6A). Postsynaptic responses to high-frequency stimulation were also occluded in the continuous 
Figure 5. Change in the current/voltage relationship for NTS neurons by IS, $3 R$-ACPD. $A$, Control $I / V$ curve ( $\square$ ) was measured from a holding potential of $-55 \mathrm{mV}$ immediately prior to application of $1 S, 3 R$-ACPD $(50 \mu \mathrm{M})$. $1 S, 3 R$-ACPD $(O)$ reduced the slope conductance of the $I / V$ relationship throughout the range of test potentials. Because the postsynaptic ACPD current was always small $(<50 \mathrm{p} \Lambda)$ at potentials near the resting $V_{m}$ of NTS neurons, peak $1 S, 3 R$-ACPD currents obtained at various holding potentials following repeated exposure to $1 S, 3 R$ ACPD (see Results) were pooled as shown in $B$, which illustrates pooled data from five cells following repeat exposure to $1 S, 3 R$-ACPD. The estimated reversal potential for the postsynaptic $1 S, 3 R$-ACPD current was $-75 \mathrm{mV}$. Where absent, the SD (error bars) at a given holding potential was less than the width of the data point. $C$, Voltageclamp rccording $\left(V_{\mathrm{h}}=-50 \mathrm{mV}\right)$ illustrating that the inward current produced by $1 S, 3 R$-ACPD was reversibly occluded by the addition of $5 \mathrm{~mm} \mathrm{Ba}{ }^{2+}$. Thus, while $\mathrm{Ba}^{2+}$ itself produced an inward current in NTS neurons, $1 S, 3 R$ $A C P D$ failed to induce a further inward current in the presence of $\mathrm{Ba}^{2+}$.
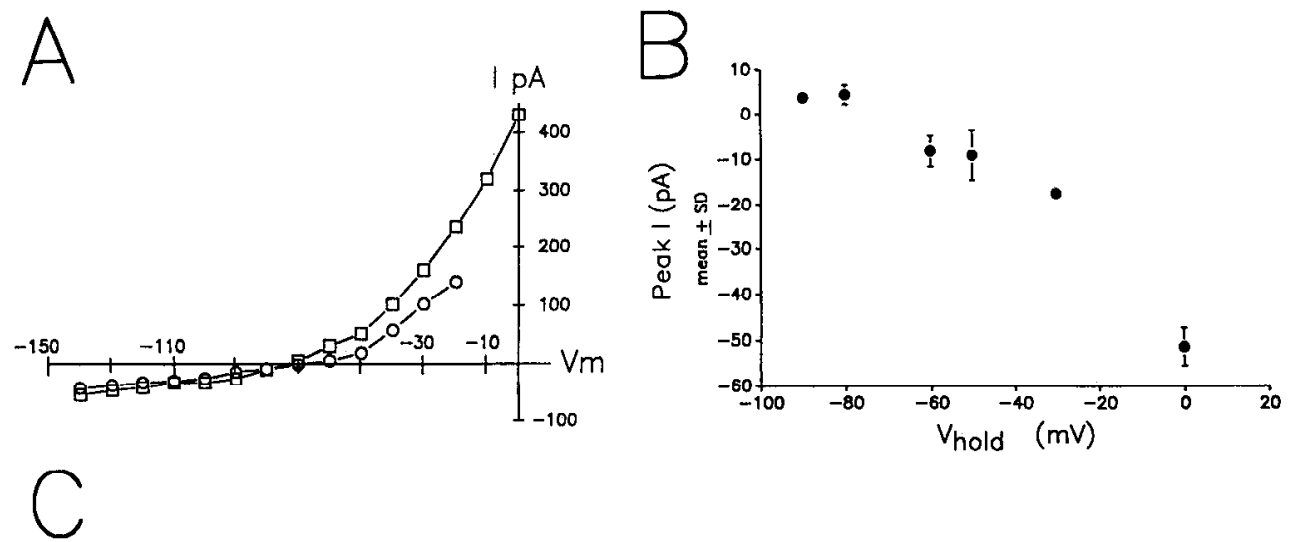

CONTROL

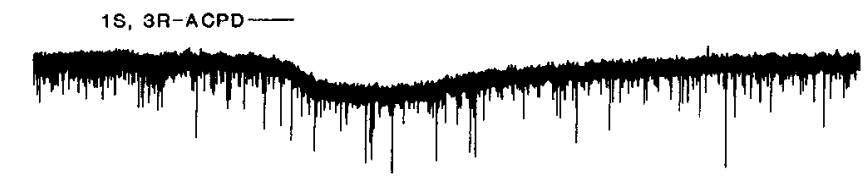

$\mathrm{BaCl}_{2}$

1S, 3R-ACPD

WASH

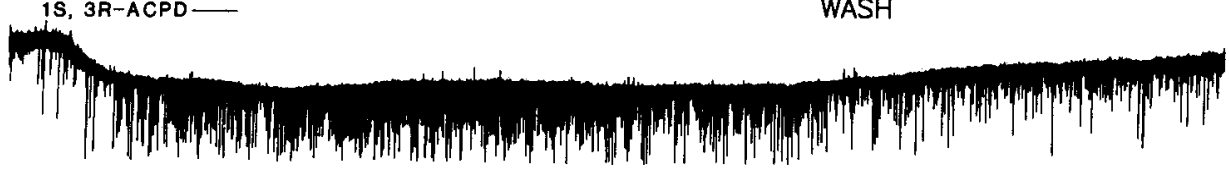

RECOVERY

1S, 3R-ACPD -

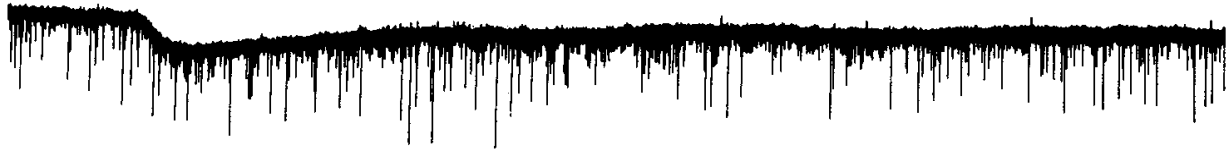

A CONTROL
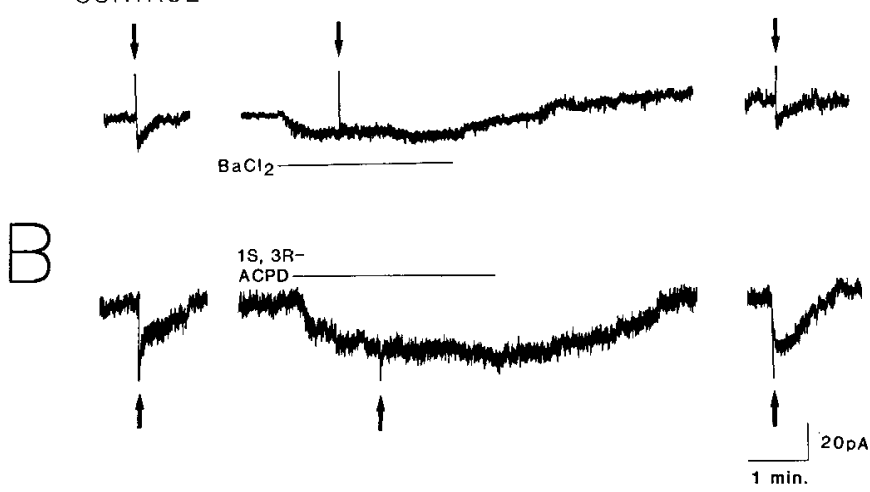

Figure 6. Voltage-clamp recordings of NTS neurons following highfrequency stimulation of the TS. $A$, Control inward current evoked by high-frequency stimulation (first arrow) of the TS $(300 \mathrm{msec}, 50 \mathrm{~Hz}, 3$ $\mathrm{V})$ in the presence of DNQX $(1 \mu \mathrm{M})$, APV $(50 \mu \mathrm{M})$, and BIC $(10 \mu \mathrm{M})$. Following the addition of $5 \mathrm{mM} \mathrm{BaCl}_{2}$, an inward current was observed. However, no additional inward current followed an identical, highfrequency stimulation of the TS (second arrow). The stimulus-induced inward current recovered following $\mathrm{Ba}^{2+}$ washout. $B$, Control inward current in another NTS neuron evoked by a high-frequency $(500 \mathrm{msec}$, $50 \mathrm{~Hz}, 4 \mathrm{~V}$ ) stimulus train (first arrow) in the presence of synaptic blockers as in $A$. The addition of $1 S, 3 R$-ACPD produced an inward current that occluded further postsynaptic responses to an identical stimulus train (second arrow). Stimulus-induced current recovered following washout of $1 S, 3 R$-ACPD. $V_{h}$ in $A$ and $B$ was $-60 \mathrm{mV}$. presence of $1 S, 3 R$-ACPD itself (Fig. $6 B ; n-5$ ), supporting the notion that synaptically released GLU may be activating postsynaptic metabotropic receptors. To confirm that high-frequency stimulation was not directly activating the postsynaptic cell by electronic spread through the slice, synaptic responses were blocked by the addition of TTX $(1 \mu \mathrm{M})$. TTX completely inhibited postsynaptic voltage or current responses to high-frequency stimulation in all cases.

\section{Discussion}

In the present study we have demonstrated that activation of metabotropic GLU receptors using $1 S, 3 R$-ACPD produces both excitatory postsynaptic and inhibitory presynaptic effects within a region of the NTS known to contain a high density of cardiac afferent projections (Donoghue et al., 1985). Such results are in keeping with a growing number of observations on synaptic cvents in the CNS which seem to be mediated by metabotropic GLU receptors (reviewed in Miller, 1991). These include a role for these receptors in the induction of long-term depression in the cerebellum (Kano et al., 1988; Linden et al., 1991), in producing long-term potentiation in the hippocampus (McGuinness et al., 1991), and in producing slow excitation of CA3 hippocampal pyramidal neurons following stimulation of mossy fibers (Charpak and Gähwiler, 1991).

In addition to the effects of exogeneously applied $1 S, 3 R$ - 
ACPD, we provide evidence that postsynaptic mechanisms, indistinguishable from those activated by metabotropic GLU receptors, can be activated by high-frequency stimulation of the TS. We also noted depression of the EPSP/IPSP complex following high-frequency stimulation of the TS. This could result from stimulation of presynaptic metabotropic receptors by synaptically released GLU and provide a physiological correlate of the presynaptic effects of $1 S, 3 R$-ACPD we have reported. However, such an interpretation would be premature for several reasons. First of all, rapid stimulation of postsynaptic 6-cyano7-dinitroquinoxaline-2,3-dione-sensitive AMPA receptors causes them to desensitize (Kiskin et al., 1986). This would reduce the size of the EPSP and, indirectly, the size of the GLUdriven component of the polysynaptic IPSP. Second, other types of presynaptic glutamate receptors exist [e.g., the L-aminophosphonobutyrate (L-AP4) receptor] whose activation also leads to a depression of GLU release (Forsythe and Clements, 1990). Thus, without specific antagonists of the L-AP4 and metabotropic GLU receptors, the relative contributions of these two entities are difficult to assess.

Until recently, activation of metabotropic glutamate receptors has been associated with stimulation of phospholipase $C$ and mobilization of intracellular $\mathrm{Ca}^{2+}$ stores (Palmer et al., 1989; Schoepp and Johnson, 1989; Schoepp et al., 1990). In some instances these effects have been shown to be blocked by L-AP3 (Miller, 1991). It is clearly important to try to relate these observations to the recently observed electrophysiological effects of $1 S, 3 R$-ACPD. As we have now demonstrated, at least some of these effects can be dissociated from any ability to mobilize $\mathrm{Ca}^{2+}$ from intracellular stores and are insensitive to the effects of L-AP3. This conclusion was also reached by Charpak et al. (1990), who found that although activation of metabotropic receptors sometimes resulted in $\mathrm{Ca}^{2+}$ mobilization in hippocampal pyramidal neurons, this effect appeared to be dissociated from the ability to depolarize the same cells.

The electrophysiological effects of $1 S, 3 R$-ACPD have been recently examined in various regions of the brain, particularly the hippocampus and the cerebellum. The present results are similar to those reported for the hippocampus where $1 S, 3 R$ ACPD excites pyramidal neurons (Stratton et al., 1989, 1990; Charpak et al., 1990) and reduces both excitatory (glutamatergic) (Baskys and Malenka, 1991; Desai and Conn, 1991; Pacelli and Kelso, 1991) and inhibitory (GABAergic) (Desai and Conn, 1991; Pacelli and Kelso, 1991) transmission. The excitatory tests of $1 S, 3 R$-ACPD in the hippocampus include direct depolarization of pyramidal neurons as well as a reduction in spike accommodation. It has been suggested that these effects are due to inhibition of $I_{\mathrm{K}(\mathrm{Ca})}$ and $I_{m}$, respectively (Charpak et al., 1990). Similar mechanisms could underlie the excitatory effects of $1 S, 3 R$-ACPD in the NTS. Three types of $\mathrm{K}^{+}$conductances have been previously described in the NTS, these being $I_{m}, I_{\mathrm{K}(\mathrm{Ca})}$, and $I_{\mathrm{A}}$ (Champagnat et al., 1986; Dekin and Getting, 1987). Indeed, we have observed that $1 S, 3 R-A C P D$ does block $I_{m}$ in these neurons (S. R. Glaum, unpublished observations). This is also consistent with the observation that the $1 S, 3 R$-ACPD-induced inward current is $\mathrm{Ba}^{2+}$ sensitive and TEA insensitive. However, the depolarizing effects of $1 S, 3 R$-ACPD could also involve a reduction in $I_{\mathrm{K}(\mathrm{leak})}$, as recently demonstrated for thalamic neurons (von Krosigk and McCormick, 1991). The inability of $1 S, 3 R$-ACPD to mobilize $\mathrm{Ca}^{2+}$ in NTS neurons is not necessarily inconsistent with a possible block of $I_{m}$ in these cells. Thus, although some studies have suggested that a rise in $\left[\mathrm{Ca}^{2+}\right]_{i}$ leads to the inhibition of $I_{m}$ (Kirkwood et al., 1991), this relationship has proved to be highly complex (Marrion et al., 1991). Other studies have suggested that activation of protein kinase $\mathrm{C}$ may be involved in the inhibition of $I_{m}$ or indeed that $\mathrm{IP}_{3}$ itself may alter the properties of this $\mathrm{K}^{+}$channel directly (Brown and Adams, 1987; Dutar and Nicoll, 1988). Thus, even in the absence of a rise in $\left[\mathrm{Ca}^{2+}\right]_{i}$, one cannot rule out a role for phospholipase $C$ activation in the signal transduction pathway activated by $1 S, 3 R$-ACPD in NTS neurons.

The molecular processes underlying the ability of $1 S, 3 R-A C P D$ to reduce neurotransmitter release in the NTS and elsewhere are unclear. In some reports, activation of metabotropic glutamate receptors has been shown to block $\mathrm{Ca}^{2+}$ currents, which could certainly produce such an effect (Lester and Jahr, 1990; see also Sahara and Westbrook, 1991). However, this action has not always been observed (Charpak et al., 1990).

It is interesting to compare the electrophysiological effects of $1 S, 3 R$-ACPD with those previously reported for muscarinic agonists in the CNS. These include decreasing or increasing a variety of $\mathrm{K}^{+}$conductances, presynaptic inhibition, and inhibition of $\mathrm{Ca}^{2+}$ currents (reviewed in Nicoll et al., 1990). It seems likely that these effects result from stimulation of different subclasses of muscarinic receptors, at least five of which appear to exist in the CNS (Bonner, 1989). It is likely that the variety of effects produced by $1 S, 3 R$-ACPD also results from activation of a family of metabotropic GLU receptors. Indeed, although the sequence of one of these receptors has been elucidated using molecular biological techniques, several incompletely characterized isoforms clearly exist as well (Houamed et al., 1991; Ohishi et al., 1991). Heterogeneity of metabotropic GLU receptors is also suggested by considering the effects of the putative metabotropic GLU receptor antagonist L-AP3. Although many of the effects of $1 S .3 R$-ACPD in the NTS and hippocampus are clearly resistant to block by this compound, it does seem to be effective in cultured neurons from the cerebellum (Irving et al., 1990; Linden et al., 1991), suggesting a difference in receptor specificity.

The present results support the notion that the kynurenic acid-insensitive effects of GLU on the baroreceptor reflex observed in vivo may be the result of metabotropic GLU receptor activation. High-frequency stimulation of afferent projections to the NTS through the TS seems to be able to produce postsynaptic excitation through the activation of metabotropic GLU receptors. It should also be pointed out that such high-frequency stimulation in the region of the TS has been shown to lead to a progressive depression in PSP amplitude in vitro (Miles, 1986), most likely through a presynaptic mechanism. Our results may also offer an explanation for this phenomenon. Such synaptic depression may underlie the central adaptation of cardiac responses to baroreceptor stimulation in that, by favoring inhibition of inhibitory neurons, metabotropic GLU receptor activation may enhance vagal output of the NTS during intense activation of baroreceptor afferents. While the importance of neurons inhibited by baroreceptor activation is poorly understood (Mifflin and Felder, 1990), by favorably reducing inhibitory mechanisms, vagal outflow could be increased. Finally, it is also clear that the development of further specific agents that act as metabotropic GLU receptors would not only provide useful tools for elucidating the physiological roles of such receptors, but could also provide novel therapeutic agents for the control of blood pressure and a variety of other important visceral processes. 


\section{References}

Baskys A, Malenka RC (1991) trans-ACPD depresses synaptic transmission in the hippocampus. Eur J Pharmacol 193:131-132.

Baskys A, Barolet AW, Carlen PL (1990a) Quisqualate induces suppression of the calcium dependent potassium current via a mechanism involving G-protcins. Can J Physiol Pharmacol 68:Aii.

Baskys A, Bernstein NK, Barolet AW, Carlen PL (1990b) NMDA and quisqualate reduce a $\mathrm{Ca}^{2+}$ dependent $\mathrm{K}^{+}$-current by a protein kinasemediated mechanism. Neurosci Lett 112:76-81.

Bonham AC, McCrimmon DR (1990) Neurones in a discrete region of the nucleus tractus solitarius are required for the Breuer-Hering reflex in rat. J Physiol (Lond) 427:261-280.

Bonner TI (1989) The molecular basis of muscarinic receptor diversity. Trends Neurosci $12: 148-151$.

Brown DA, Adams PR (1987) Effects of phorbol dibutyrate on $\mathrm{M}$-currents and $\mathrm{M}$-current inhibition in bullfrog sympathetic neurons. Cell Mol Neurobiol 7:255-269.

Champagnat J, Jacquin T, Richter DW (1986) Voltage-dependent currents in neurones of the nuclei of the solitary tract of rat brainstem slices. Pflucgers Arch 406:372-379.

Charpak S, Gähwiler BH (1991) Glutamate mediates a slow synaptic response in hippocampal slice cultures. Proc R Soc Lond [Biol] 243: 221-226.

Charpak S, Gähwiler BH, Do KQ, Knöpfel T (1990) Potassium conductances in hippocampal neurons blocked by excitatory amino acid transmitters. Nature 347:765-767.

Dekin MS, Getting PA (1987) In vitro characterization of neurons in the ventral part of the nucleus tractus solitarius. II. Ionic basis for repetative firing patterns. J Neurophysiol 58:215-229.

Desai MA, Conn PJ (1991) Excitatory effects of ACPD receptor activation in the hippocampus are mediated by direct effects on pyramidal cells and blockade of synaptic inhibition. J Neurophysiol 66: 40-52.

Donoghue S, Felder RB, Gilbey MP, Jordan D, Spycr KM (1985) Postsynaptic activity evoked in the nucleus tractus solitarius by carotid sinus and aortic nerve afferents in the cat. J Physiol (Lond) 360:261273.

Drewe JA, Miles R, Kunze DL (1990) Excitatory amino acid receptors of guinea pig medial nucleus tractus solitarius neurons. Am J Physiol 259:1389-1395.

Dutar P, Nicoll RA (1988) Stimulation of phosphatidyl-inositol (PI) turnover may mediate the muscarinic suppression of the M-current in hippocampal pyramidal cells. Neurosci Lett 85:89-94.

Forsythe ID, Clements JD (1990) Presynaptic glutamate receptors depress excitatory monosynaptic transmission between mouse hippocampal neurons. J Physiol (Lond) 429:1-16.

Grynkiewicz G, Poenie M, Tsien RY (1985) A new generation of $\mathrm{Ca}^{2+}$ indicators with greatly improved fluorescence properties. J Biol Chem 260:3440-3450.

Horikoshi T, Asanuma A, Yanagisawa K, Anzai K, Goto S (1989) Regional distribution of metabotropic glutamate response in the rat brain using Xenopus oocytes. Neurosci Lett 105:340-343.

Houamed KM, Kuijper JL, Gilbert TL, Haldeman BA, O'Hara PJ, Mulvihill ER, Almers W, Hagen FS (1991) Cloning, expression and gene structure of a G-protein-coupled glutamate receptor from rat brain. Science 252:1318-1320.

Irving AJ, Schofield JG, Watkins JC, Sunter DC, Collingdridge GL (1990) $1 S, 3 R$-ACPD stimulates and L-AP3 blocks $\mathrm{Ca}^{2+}$ mobilization in rat cerebellar neurons. Eur J Pharmacol 186:363-365.

Kano M, Kato M, Chang HS (1988) The glutamate receptor subtype mediating parallel fibre-Purkinje cell transmission in rabbit cerebellar cortex. Neurosci Res 5:325-337.

Kirkwood A, Simmons MA, Mather RJ, Lisman J (1991) Muscarinic suppression of the M-current is mediated by a rise in internal $\mathrm{Ca}^{2+}$ concentration. Neuron 6:1009-1014.

Kiskin NI, Krishtal OA, Tsyndrenko AYA (1986) Excitatory amino acid receptors in hippocampal neurons: kainate fails to desensitize them. Neurosci Lett 631:225-230.

Leone C, Gordon FJ (1989) Is L-glutamate a neurotransmitter of baroreceptor information in the nucleus of the tractus solitarius? J Pharmacol Exp Ther 250:953-962.

Lester RAJ, Jahr CE (1990) Quisqualate receptor mediated expression of calcium currents in hippocampal neurons. Neuron 4:741-749.
Linden DJ, Dickinson MH, Smeyne M, Connor JA (1991) A longterm depression of AMPA currents in cultured cerebellar Purkinje neurons. Neuron 7:81-89.

Lovinger DM (1991) trans-ACPD decreases synaptic excitation in rat striatal slices through a presynaptic action. Neurosci Lett 129:17-21.

Manzoni O, Fagni L, Pin J-P, Rassendren F, Poulat F, Sladecczek F, Bockacrt J (1990) (trans)-1-Amino-cyclopentyl-1,3-dicarboxylate stimulates quisqualate phosphoinositide-coupled receptors but not ionotropic glutamate receptors in striatal neurons and Xenopus oocytes. Mol Pharmacol 38:1-6.

Marrion NV, Zucker RS, Marsh SJ, Adams PR (1991) Modulation of $\mathrm{M}$-current by intracellular $\mathrm{Ca}^{2+}$. Neuron 6:535-545.

Masu M, Tanabe Y, Tsuchida K, Shigemoto R, Nakanishi S (1991) Sequence and expression of a metabotropic glutamate receptor. $\mathrm{Na}$ ture 349:760-765.

Mayer M, Westbrook GL (1987) The physiology and excitatory amino acids in the vertebrate central nervous systems. Prog Neurobiol 28 $197-276$

McGuinness N, Anwyl R, Rowan M (1991) trans-ACPD enhances longterm potentiation in the hippocampus. Eur J Physiol 197:231232.

Meeley MP, Underwood MD, Talman WT, Reis DJ (1989) Content and in vitro release of endogenous amino acids in the area of the nucleus of the solitary tract of the rat. $J$ Neurochem 53:1807-1817.

Mifflin SW, Felder RB (1990) Synaptic mechanisms regulating cardiovascular afferent inputs to solitary tract nucleus. Am J Physiol 28 : 653-661.

Miles R (1986) Frequency dependence of synaptic transmission in nucleus of the solitary tract in vitro. J Neurophysiol 55:1076-1090.

Miller RJ (1991) Metabotropic glutamate receptors reveal their true colors. Trends Pharmacol Sci 12:365-368.

Murphy SN, Miller RJ (1988) A glutamate receptor regulates $\mathrm{Ca}^{2+}$ mobilization in hippocampal neurons. Proc Natl Acad Sci USA 85: 8732-8741.

Nicoll RA, Malenka RC, Kaucr JA (1990) Functional comparison of neurotransmitter receptor subtypes in mammalian central nervous system. Physiol Rev 70:513-565.

Ohishi H, Shigemoto R, Tanabe Y, Masu M, Nakanishi S, Mizuno N (1991) A family of metabotropic glutamate receptors: differential distributions of mRNA in rat brain. Neurosci Res [Suppl] 16:S15.

Pacelli GJ, Kelso SR (1991) trans-ACPD reduces multiple components of synaptic transmission in the rat hippocampus. Neurosci Lett $132: 267-269$

Palmer E, Monaghan DT, Cotman CW (1989) trans-ACPD, a selective agonist of the phosphoinositide-coupled excitatory amino acid receptor. Eur J Pharmacol 166:585-587.

Sahara Y, Westbrook GL (1991) trans-ACPD blocks high threshold calcium currents on cultured hippocampal neurons. Soc Neurosci Abstr 17:1168.

Schoepp D, Bockaert J, Sladeczek F (1990) Pharmacological and functional characteristics of metabotropic excitatory amino acid receptors. Trends Pharmacol Sci 11:508-515.

Schoepp DD, Johnson BG (1989) Inhibition of excitatory amino acidstimulated phosphoinositide hydrolysis in the neonatal rat hippocampus by 2-amino-3-phosphonopropionate. J Neurochem 53:1865-1868.

Stratton KR, Worley PF, Baraban JM (1989) Excitation of hippocampal neurons by stimulation of glutamate $Q_{p}$ receptors. Eur J Pharmacol 173:235-237.

Stratton KR, Worley PF, Baraban JM (1990) Pharmacological characterization of phosphoinositide linked glutamate receptor excitation of hippocampal neurons. Eur J Pharmacol 186:357-361.

Sugiyama H, Ito I, Watanabe M (1989) Glutamate receptor subtypes may be classified into two major categories: a study on Xenopus oocytes injected with rat brain mRNA. Neuron 3:129-132.

Talman WT (1989) Kynurenic acid microinjected into the nucleus tractus solitarius of the rat blocks the arterial baroreflex but not responses to glutamate. Neurosci Lett 102:247-252.

von Krosigk M, McCormick DA (1991) Glutamate metabotropic receptor activate modulator thalamaic relay neuronal activity. Soc Neurosci Abstr 17:254.

Zheng F, Gallagher JP (1991) trans-ACP elicited oscillation of membrane potentials in rat dorsolateral septal nucleus neurons recorded intracellularly in vitro. Neurosci Lett 125:147-150. 